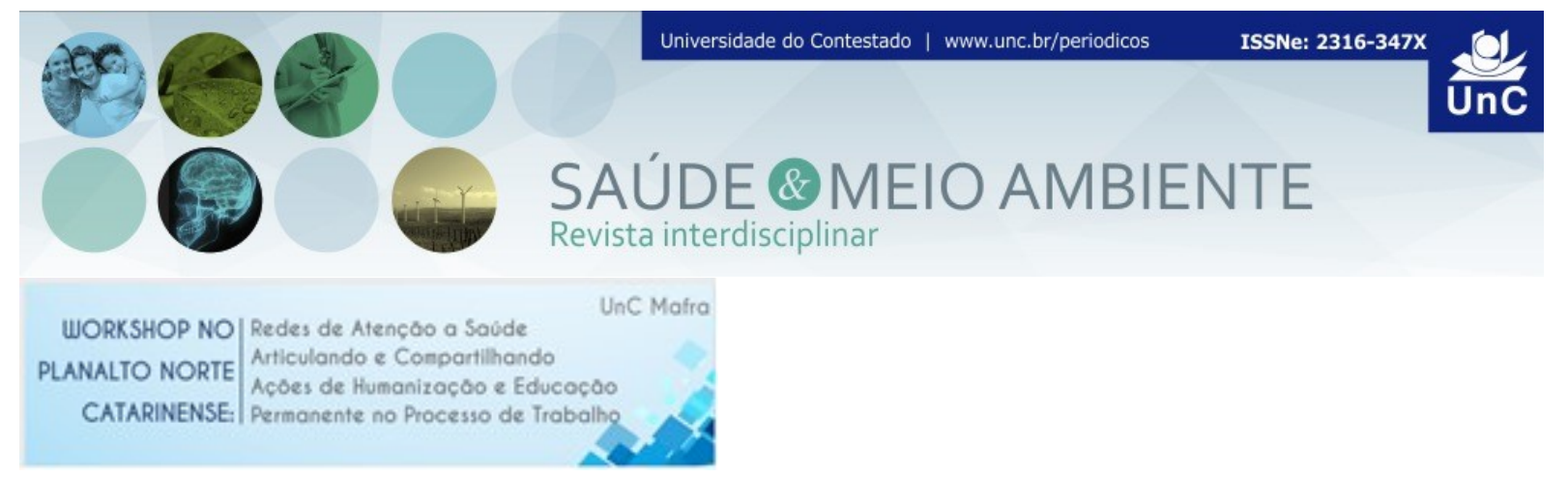

\title{
ARRANJO PRODUTIVO LOCAL PARA PRODUÇÃO DE PLANTAS MEDICINAIS NATIVAS NA ÁREA DE PRESERVAÇÃO PERMANENTE DO RIO VERMELHO, SÃO BENTO DO SUL
}

\author{
Ana Carla Koetz Prade ${ }^{1}$ \\ Manuel Rodriguez Del Olmo \\ Suzieli Lamin ${ }^{3}$ \\ Paulo Schwirkowski ${ }^{4}$
}

\section{RESUMO}

Introdução: Arranjos Produtivos Locais (APLs) são aglomerações territoriais de agentes econômicos que apresentam especialização produtiva e mantêm vínculos de articulação, interação, cooperação a aprendizagem entre si e com outros atores locais, tais como: governo, associações empresariais, instituições de crédito, ensino e pesquisa, produtores rurais entres outros. Este projeto visa a formação de um Arranjo Produtivo Local para produção de espécies arbóreas medicinais na região de Preservação Ambiental da Bacia do Rio Vermelho Humboldt, localizada em São Bento do Sul. Relato de caso: O município iniciou o Projeto Farmácia Viva em março de 2017 e entre seu elenco de espécies medicinal a serem cultivadas encontra-se duas arbóreas: a Maytenus ilicifolia, conhecida como Espinheira Santa e a Schinus terebenthifolius, conhecida como Aroeira vermelha entre outros nomes populares. Por serem espécies de grande porte, ocorre a dificuldade de cultiva-las em hortas, sendo necessário outras alternativas para sua produção. Neste ínterim, a Secretaria do Meio Ambiente, junto com o Serviço Autônomo de Água e Esgoto (SAMAE), colocaram à disposição da Secretaria de Saúde e do Farmácia Viva as áreas de Preservação Ambiental do Programa de Pagamento por Serviços Ambientais do Rio Vermelho (PSA) para o cultivo destas espécies dentro das propriedades que participam deste programa. Metodologia: Os proprietários das áreas de preservação receberão mudas de Maytenus ilicifolia e Schinus terebenthifolius que serão cultivadas junto ao leito dos rios que permeiam suas propriedades. Após o desenvolvimento mínimo necessário das duas espécies, os produtores farão o extrativismo sustentável das partes de interesse ao programa de Fitoterapia e fornecerão ao município. A produção destas espécies medicinais entrará no PSA como mais um item de valoração na escala de

\footnotetext{
${ }^{1}$ Farmacêutica, Coordenadora do Projeto Farmácia Viva, Prefeitura de São Bento do Sul, SC. Santa Catarina. Brasil. E-mail: ana cruz@saobentodosul.sc.gov.br

${ }^{2}$ Secretário de Saúde do município de São Bento do Sul, Prefeitura Municipal de São Bento do Sul, SC. Santa Catarina. Brasil.

${ }^{3}$ Coordenadora Departamento de Atenção Básica, Prefeitura Municipal de São Bento do Sul, SC.

Santa Catarina. Brasil. E-mail: esf@saobentodosul.sc.gov.br

${ }^{4}$ Chefe da Divisão de Resíduos Sólidos Urbanos, Serviço Municipal Autônomo de Água e Esgoto, Prefeitura de São Bento do Sul, SC. Santa Catarina. Brasil. E-mail: paulo@samaesbs.sc.gov.br
} 
ações de preservação dentro do programa, cujo objetivo é realizar o pagamento aos proprietários que cumprirem estas ações. Resultados e Conclusão: $O$ resultado esperado deste projeto é multisetorial: no âmbito da saúde objetiva-se o suprimento de matéria-prima para o Projeto Farmácia Viva com consequente fortalecimento do projeto; no âmbito do meio ambiente, o fortalecimento do Programa de Pagamento de Serviços Ambientais e a preservação do manacial aquífero que abastece o município e no âmbito econômico a redução à longo prazo da compra de medicamentos, devido ao fortalecimento de programas de prevenção de doenças como o Farmácia Viva, e a preservação dos recursos hídricos naturais que abastecem o município.

Palavras-Chave: Farmácia Viva. Fitoterapia. Atenção Básica. Práticas Integrativas e Complementares. Meio ambiente.

Resumo recebido em: 12/12/2017

Resumo aprovado em: 17/12/2017

Resumo publicado em: 20/12/2017 